\title{
Georges Didi-Huberman e o sintoma das imagens
}

\author{
Laís Kalena Salles Aragão ${ }^{7}$ \\ DOI 10.20396/eha.vil4.3395
}

\section{Introdução}

As imagens de arte frequentemente despertam o desejo de saber sobre elas. Assim, estar diante do universo artístico implica muitas vezes, em nós, a busca da verdade acerca do que vemos. De acordo com Georges Didi-Huberman, na obra Diante da Imagem, alguns historiadores da arte, sobretudo Erwin Panofsky, utilizaram-se da epistemologia kantiana como instrumento essencial à reflexão acerca dos limites da sua própria disciplina. Os efeitos dessa escolha refletiram-se profundamente na constituição da história da arte enquanto conhecimento científico que pretende promover um saber seguro e exato sobre a arte. A análise das imagens assimila, assim, o tom de certeza em relação ao seu objeto. Deve-se, contudo, desconfiar. Afinal, seria mesmo a história da arte baseada na crítica kantiana do conhecimento portadora de todo o saber sobre as imagens, de toda a certeza, de toda a exatidão? Seria ela uma disciplina fundada sobre uma epistemologia segura?

Ao investigar tais problemas em história da arte, encontra-se o ponto nevrálgico da disciplina: a sua limitação diante do que autor denomina de "sintoma", isto é, aquilo "que desagrega toda a unidade discursiva, que se intromete, rompe a ordem da Ideia, abre os sistemas, impõe um impensável"z; trata-se do instante em que a convicção do "saber" se esbarra com a incerteza do "nãosaber". Em termos gerais, o autor afirma que "a história da arte fracassa em compreender a imensa constelação dos objetos criados pelos homens em vista de uma eficácia do visual quando busca integrá-los ao esquema convencional do domínio do visível”3. Tendo em vista que a história da arte que propõe o domínio, a certeza e a exatidão do saber ignora - e mesmo rejeita - a natureza sintomática do seu objeto de investigação, pretendo, neste artigo, abordar a seguinte questão: de acordo com Ceorges Didi-Huberman, qual seria o método mais eficaz para lidar com o sintoma das imagens? Busco, assim, demonstrar, de maneira preliminar, como a recorrência ao campo de formulações freudianas, mais especificamente, ao conceito de sintoma e à sobredeterminação, permite,

\footnotetext{
1 Graduada em licenciatura em História pela Universidade Federal de Sergipe (DHI/UFS). Este artigo foi orientado pelo Prof. Dr. Vladimir de Oliva Mota. E-mail: lais.kalena@hotmail.com

2 DIDI-HUBERMAN, Georges. Diante da Imagem: questão colocada aos fins de uma história da arte. Tradução: Paulo Neves. São Paulo: Editora 34, 2013, p. 221-222.

3 Ibid., p. 39.
} 
segundo Georges Didi-Huberman, renunciar às idealizações mantidas pela abordagem histórica da arte baseada na epistemologia kantiana e estender a compreensão acerca dos objetos que fundam este conhecimento.

Assim, a partir da leitura das obras Diante da Imagem, Diante do Tempo e Invenção da Histeria, irei, inicialmente, apresentar uma das críticas de Ceorges Didi-Huberman à análise das imagens de arte notabilizada por Erwin Panofsky. Em seguida, irei justificar a recorrência de Didi-Huberman a Freud e contrapor a insuficiência do método de investigação de Panofsky frente ao conceito de sintoma. Por fim, irei tratar da sobredeterminação freudiana empregada por Didi-Huberman como alternativa metodológica capaz de lidar com as problemáticas ignoradas ou mesmo rejeitadas por uma história da arte acadêmica.

A história da arte panofskyana e os limites de sua prática

Georges Didi-Huberman interrogou, em parte de sua vasta produção bibliográfica, os limites metodológicos de uma história da arte panofskyana. Erwin Panofsky é, sobretudo, o historiador da arte que fixou, através dos seus Estudos em Iconologia, da obra Significado nas Artes Visuais e dentre tantas outras, um método que buscava extrair a significação dos elementos pictóricos das imagens de arte: a iconologia. De acordo com Didi-Huberman, quando os historiadores da arte decidiram produzir um discurso objetivo acerca do seu objeto, "o kantismo da razão pura se tornou como que uma passagem obrigatória para todos aqueles que buscavam refundar sua disciplina e redefinir 'a arte' como um objeto de conhecimento, não como tema de disputas acadêmicas"4. Para ele, há um mal-estar vivido na história da arte acadêmica: a insuficiência do método iconológico herdado por Erwin Panofsky. Ao se aplicarem a criticar a extensão e os limites da sua própria disciplina, os historiadores da arte julgaram-se no comando do saber que produziam. Assim, buscaram, nas imagens de arte, signos, símbolos ou a manifestação de númenos estilísticos e asseguraram estar conscientes da sua prática. Isto implica, segundo Didi-Huberman, domínio dos métodos e conceitos que fundam a disciplina e garantia de rigor em suas análises 5 .

Panofsky é especialmente notabilizado pela intensidade da sua exigência teórica: um verdadeiro ápice do movimento crítico que o autor de Diante da Imagem busca delimitar ${ }^{6}$. Através do mé-

\footnotetext{
4 Ibid., p. 124.

5 Ibid., p. 126

6 Ibid., p. 125
} 
todo iconológico e do seu sistema de análise, objetivou-se transpor o nível da percepção e acessar a esfera da significação das obras de arte, identificando, inicialmente, os elementos mais simples (objetos e acontecimentos), que constituem o limiar iconográfico, e, consecutivamente, os mais complexos (temas e conceitos), compondo o limiar iconológico. Assim, assinala Didi-Huberman, a história da arte teria acesso a seus ambiciosos fins: identificar os princípios, os fundamentos, a essência dos fenômenos artísticos, tendo em vista condições metafísicas fundamentais, isto é, que revelam a universalidade objetiva e os sentidos imanentes por detrás das obras de arte ${ }^{7}$. Contudo, deve-se desconfiar. Quais seriam, para Ceorges Didi-Huberman, os efeitos da prática desta história da arte?

Em Diante da Imagem, o filósofo francês convida-nos a olhar o afresco intitulado "Anunciação", pintado pelo frade dominicano Fra Angelico no convento de San Marco, em Florença. Trata-se de uma cena bastante célebre e revisitada: o relato de São Lucas da Anunciação, tal como encontra-se no Evangelho. A obra desperta o interesse do autor, dentre outras razões, devido ao efeito ofuscante que o predomínio da cor branca nos impõe. Tal seria, contudo, exatamente o seu defeito. Se esperássemos encontrar a eficácia desta imagem na sua capacidade de apresentar objetos e acontecimentos que pudessem ser traduzidos em temas e conceitos que nos fornecessem unidades de saber; se esperássemos que esta imagem nos contasse uma história através da riqueza de seus elementos e detalhes (como o olhar treinado dos historiadores de arte familiarizados com as Anunciações do Quattrocento buscaria), ficaríamos decepcionados, pois Fra Angelico o faz, como aponta Didi-Huberman, de maneira muito pobre e sumária ${ }^{8}$. A isto, o autor indaga: como deveríamos, então, situar Fra Angelico nas estruturas da história da arte? Pintor muito sumário, minimalista? Pintor naïf, no sentido pejorativo do termo? Ou então pintor do invisível, "em que uma metafísica é possível, desde o simples fora de campo (hors-champ) inexistente do quadro até o mais-além ideal da obra inteira"? ? Para ele:

Todo campo de saber se constituiu imaginando-se terminado, "vendo-se" possuir inteiramente a suma do saber que ainda não possui e para o qual se constitui. Ele se constitui, portanto, votando-se a um ideal. Mas, ao fazer isso, arrisca-se também a votar seu objeto ao ideal em questão: sujeita o objeto a esse ideal, imaginando-o, vendo-o ou prevendo-oem suma, dando-lhe forma e inventando-o por antecipação ${ }^{10}$.

\footnotetext{
7 Ibid., p. 141.

8 Ibid., p. 19-21.

9 Ibid., p. 22.

10 Ibid., p. 115-116.
} 
Contudo, a tentativa de "resolver" o problema da subjetividade não passa, para DidiHuberman, de uma forma tirânica de lidar com o que aparenta não fazer sentido, com o que parece não significar, com o que não se sabe acerca do que se olha, pois cria a arte à imagem do método que fundamenta a elaboração de um discurso histórico que se pretende objetivo"1.

A história dos sintomas: uma história dos "não-sentidos"

Segundo Didi-Huberman, mesmo quando se aplicam a criticar a extensão e os limites da sua própria disciplina, os historiadores da arte, contudo, raramente arriscam olhar o sintoma, pois observá-lo os levaria inevitavelmente a abandonar a posição de vantagem e poder do "sujeito que sabe". A isso, Georges Didi-Huberman faz as seguintes perguntas:

[...] seria a significação o único parâmetro a que se pode referir o conteúdo de uma obra de arte, se essa noção tem um sentido? Não contêm as obras de arte algo mais que significação? Seria realmente insensato imaginar uma história da arte cujo objeto fosse a esfera de todos os não-sentidos contidos na imagem? ${ }^{12}$.

Para viabilizar a elaboração disso que denomina de história dos não-sentidos das imagens, Didi-Huberman recorre à obra de Sigmund Freud por identificar nela o esforço em tentar constituir um saber não especular, capaz de pensar o trabalho do não-saber. Em A Interpretação dos Sonhos, ao investigar o trabalho de figurabilidade próprio às formações do inconsciente, Freud é levado, para o filósofo, a uma compreensão nova e mais decisiva da noção de sintoma. Isto porque o psicanalista propõe um modelo visual que rompe tanto com a concepção clássica do disegno (e sua transparência mimética) quanto com a imagem-monograma (e sua homogeneidade sintética), extraída do esquema kantiano ${ }^{13}$.

Embora Freud não tenha comparado o sonho com um quadro ou um desenho figurativo, Didi-Huberman estende tal raciocínio ao mundo das imagens de arte por identificar na obra freudiana todos os elementos de uma crítica profunda do conhecimento a partir da qual podemos reabrir a questão do saber e analisar o estatuto da história da arte sem, para tal, omitir a existência dos sintomas. Mas em que consiste um sintoma? O que a expressão "sintoma" implica? Para o autor, trata-se de uma palavra difícil de apreender. Em Diante do Tempo, o filósofo afirma que "ela não

\footnotetext{
11 lbid., p. 116.

12 Ibid., p. 161.

13 Ibid., p. 191-192.
} 
designa uma coisa isolada, nem mesmo um processo que poderíamos reduzir a um ou dois vetores ou a um número preciso de componentes"14.

Em Diante da Imagem, Didi-Huberman afirma:

Acidente soberano é o que se chama, estritamente falando, um sintoma s, palavra a ser entendida com toda a extensão e o rigor semiológicos que Freud Ihe conferiu. Um sintoma [...] será, por exemplo, o momento, a imprevisível e imediata passagem de um corpo à aberração de uma crise, de uma convulsão histérica, de uma extravagância de todos os movimentos e de todas as atitudes: de repente os gestos perderam sua "representatividade", seu código $0^{15}$.

Ele defende, assim, que Freud supôs que "o acidente - o gesto insensato, informal, incompreensível, 'não icônico' - era claramente soberano [...]”, pois “[...] tal momento libera uma significância"16. Para o fundador da psicanálise, trata-se de uma "simultaneidade contraditória"17: entre o estilhaço e a dissimulação, entre o acidente e a soberania, entre o acontecimento e a estrutura ${ }^{18}$. A palavra sintoma relaciona-se, portanto, ao mesmo tempo, àquilo que interrompe a ordem e ao que instaura uma estrutura significante.

A isso, o autor acrescenta que "o que a imagem-sintoma interrompe não é senão o curso da representação" ${ }^{\prime \prime}$. Na obra Invenção da Histeria, Didi-Huberman afirma que "a abordagem freudiana do sintoma me permitiu renunciar às simplificações com que a história da arte se satisfaz, com demasiada frequência"2o; permitiu-lhe ainda "renunciar às idealizações que uma abordagem acadêmica da arte mantem"21. Para ele, falar de sintoma no campo da história da arte:

[...] não é buscar doenças, ou motivações mais ou menos conscientes, ou desejos recalcados por trás do quadro, supostas "chaves de imagens", como se falava outrora de chaves dos sonhos; é, mais simplesmente, buscar avaliar um trabalho da figurabilidade, estando entendido que toda figura pictórica supõe "figuração", assim como todo enunciado poético supõe enunciação ${ }^{22}$.

Aqui, a análise do trabalho da figurabilidade das imagens da arte pressupõe que as palavras

\footnotetext{
14 Id., 2017, p. 43.

15 Id., 2013, p. 333 (grifo do autor).

16 Ibid., p. 333 (grifo do autor).

17 Ibid., p. 333, apud FREUD, 1973, p. 155.

18 Ibid., p. 334.

19 Id., 2017. p. 44 (grifo do autor).

20 Id., 2015, p. 422.

21 Id., 2015, p. 422.

22 Id., 2013, p. 335.
} 
"imagem" e "figurabilidade" escapam à noção habitual e restrita do que se chama arte "figurativa", isto é, "representativa de um objeto ou de uma ação do mundo natural"23, aproximando-se mais daquilo que Didi-Huberman define como "figurar", isto é, "[...] modificar figuras, e portanto em efetuar o trabalho insistente de uma desfiguração no visível"24. Discutir o trabalho de figurabilidade, para Didi-Huberman, trata-se, portanto, de uma forma de estender a compreensão acerca dos objetos que fundam o conhecimento histórico sobre a arte.

\section{A sobredeterminação freudiana}

Assim, ao buscar a resposta para o problema dos sintomas das imagens no campo das formulações freudianas, Georges Didi-Huberman é levado a considerar, como Freud, outro método de interpretação que fosse capaz de dialogar com a natureza imprevisível e contraditória - embora significante - dos sintomas: a sobredeterminação. O psicanalista alemão conclui, em seus estudos sobre a interpretação dos sonhos, que aquela interpretação que, à primeira vista, parece plausível, completa e suficiente pode ser sobreinterpretada, isto é, sobreposta por uma outra camada de significações. Freud acrescenta que já teve:

[...] ocasião de assinalar que, de fato, nunca é possível ter certeza de que um sonho foi completamente interpretado. Mesmo que a solução pareça satisfatória e sem lacunas, resta sempre a possibilidade de que o sonho tenha ainda outro sentido 25 .

Isto porque, de acordo com o médico alemão, "os sonhos não têm a seu dispor meios de representar essas relações lógicas [fornecidas, por exemplo, pelas conjunções 'porque', 'como', 'ou... ou'] entre os pensamentos do sonho" ${ }^{26}$, pois ele apresenta visualmente o conjunto de elementos que um discurso representativo teria normalmente diferenciado ou inferido uns dos outros.

Didi-Huberman afirma, em Diante da Imagem, que a interpretação deve levar em conta o risco que os sintomas apresentam ao pensamento "a fim de indicar - nem que seja apenas indicar - o intratável que constitui seu objeto"27. Em outras palavras, o filósofo propõe a sobredetermina-

\footnotetext{
23 Ibid., p. 16.

24 Ibid., p. 270 (grifo do autor).

25 FREUD, Sigmund. A Interpretação dos Sonhos ( $1^{\circ}$ Parte). Tradução: Walderedo Ismael de Oliveira. In: FREUD, Sigmund. Obras Psicológicas Completas de Sigmund Freud: edição standard brasileira. 2. ed. Rio de Janeiro: Imago, 1987. v. 4.

26 Ibid., p. 299-300 (grifo nosso).

27 DIDI-HUBERMAN, Georges. Diante da Imagem: questão colocada aos fins de uma história da arte. Tradução: Paulo Neves. São Paulo: Editora 34, 2013, p. 346.
} 
ção como paradigma de investigação, pois ela nos dá a ver novos elos e associações possíveis em um mesmo plano, embora ponha em risco a exatidão interpretativa oferecida pela dedução. Nesse sentido, ele conclui, em Diante do Tempo, que "[...] a história das imagens é uma história de objetos impuros, complexos, sobredeterminados" e que "[...] a esses objetos sobredeterminados corresponde um saber sobreinterpretativo"28 - embora tal "saber sobreinterpretativo" seja tido no jargão dos historiadores como um grave insulto, uma vez que transforma o tão almejado "tom de certeza" em uma meta inalcançável ${ }^{29}$.

\section{Conclusão}

Ceorges Didi-Huberman é levado a considerar, assim como Freud, outro método de interpretação que fosse capaz de dialogar com a natureza imprevisível e contraditória - embora significante - dos sintomas: a sobredeterminação. Isto faz-se necessário a fim de viabilizar a existência disso que o autor denomina de "história dos sintomas" das artes visuais, isto é, uma história que admita a natureza dialética das imagens de arte. De acordo com Didi-Huberman, embora a sobredeterminação ponha em risco a exatidão interpretativa oferecida pela dedução, ela nos dá a ver novos elos e associações possíveis em um mesmo plano, estendendo, assim, a compreensão acerca dos objetos que fundam o conhecimento histórico sobre a arte. A incerteza do não-saber oferecida pelas imagens sintomáticas exige do olho que as vê um certo despojamento de signos, símbolos e númenos estilísticos, votado, assim, a uma perda; exige, portanto, uma desestruturação do olhar que as vê e a sua consequente reestruturação, abandonando o idealismo da história da arte ${ }^{30}$. 


\section{Referências Bibliográficas}

DIDI-HUBERMAN, Georges. Diante da Imagem: questão colocada aos fins de uma história da arte. Tradução: Paulo Neves. São Paulo: Editora 34, 2013.

DIDI-HUBERMAN, Georges. Diante do Tempo: história da arte e anacronismo das imagens. Tradução: Vera Casa Nova e Márcia Arbex. Belo Horizonte: Editora UFMG, 2017.

DIDI-HUBERMAN, Georges. Invenção da Histeria: Charcot e a iconografia fotográfica da Salpêtrière. Tradução: Vera Ribeiro. Rio de Janeiro: Contraponto, 2015.

FREUD, Sigmund. A Interpretação dos Sonhos ( $1^{\circ}$ Parte). Tradução: Walderedo Ismael de Oliveira. In: FREUD, Sigmund. Obras Psicológicas Completas de Sigmund Freud: edição standard brasileira. 2. ed. Rio de Janeiro: Imago, 1987. v. 4. 